\title{
MEASURING INNOVATION PERFORMANCE OF DEVELOPING REGIONS: LEARNING AND CATCH-UP IN PROVINCES OF IRAN
}

\author{
Sepehr GHAZINOORY, Parisa RIAHI ${ }^{\mathrm{a}}$, Adel AZAR ${ }^{\mathrm{a}}$, Tahereh MIREMADI ${ }^{\mathrm{b}}$ \\ ${ }^{a}$ Faculty of Management and Economics, Tarbiat Modares University, Tehran, Iran \\ bIranian Research Organization for Science and Technology, Tehran, Iran
}

Received 27 November 2012; accepted 26 October 2013

\begin{abstract}
Common innovation performance measures, which are based on research and development activities, are not relevant to dominant innovation behaviour of developing countries. The main functions of the innovation system of developing countries are capture, imitation, learning by doing and diffusion of knowledge, to reduce technology gaps with technology frontiers. Hence, the purpose of measuring innovation performance in a developing geographical area should be the evaluation on its success in technological learning and catching-up. Using the learning and technology gap concepts, in this paper we develop a novel model of measuring innovation performance of developing countries/regions, based on common regional statistics. In the virtual absence of mandatory firm level surveys, this model can provide a useful method to compare the innovation behaviour of regions for policymaker. Running the model with the data from the Iranian provinces, the paper concludes each province has its own specific innovation behaviour stemming from different historical development paths and geographical characteristics.
\end{abstract}

Keywords: innovation performance, regional innovation, developing countries, technological learning, catch-up, technology gap.

JEL Classification: R11, O31, O33.

\section{Introduction}

Innovation has significant consequences for socio-economic variables, such as GDP, productivity growth and employment (Freeman 2002; Griliches 1979; Edquist et al. 2001), which attracts the attention of policymakers. Furthermore, the study of innovation behaviour of countries and regions is important for developmental policy research (Chaminade et al. 2009). Yet, despite the importance of national/regional innovation performance measurement, there is no consensus about its definition and this concept remains largely unclear. Hence, there

Corresponding author Sepehr Ghazinoory

E-mail: ghazinoory@modares.ac.ir 
is no agreed measure for innovation performance, and scholars, based on their approach to innovation, have their own interpretation and use different methods for measurement, accordingly (Edquist, Zabala 2009; Fritsch, Slavtchev 2006; Broekel, Brenner 2007). In addition, the innovation processes have different patterns and styles in different regions (Jensen et al. 2007). Therefore, it seems that the existing methods and indices are not necessarily appropriate in measuring innovations in all regions (Sutz 2012). One size does not fit all areas due to different social-economical contexts.

Innovation in developing countries is based on diffusion and use of first, the inner stock of knowledge; second, the created knowledge by local firms; and finally, the external knowledge (Kim 1997). In developing countries, interactive learning and imitation are the pillars of innovation activities. Unlike developed countries, this process rarely creates radical breakthrough in scientific and technological knowledge. The process typically brings about small changes by incremental innovations and gradual reduction of the technology gap. However, the existing common measures, even those recommended by international organizations, such as the Global Innovation Index or the European Innovation Scoreboard, have little relevance to the features of the innovation process in developing countries. There is also an increasing tendency to use advance methods, such as Data Envelopment Analysis (DEA) method, for measuring and benchmarking regional innovation systems which suffer the same limitation (Zabala-Iturriagagoitiaa et al. 2007; Wu et al. 2010). Furthermore, while the learning concept becomes a key concept in the innovation systems literature, none of common innovation performance measures has been provided with an operational definition for this concept to use it.

Studies on innovation systems of developing countries have begun since 1999 with the papers written by Arocena, Sutz (1999) and Gu (1999). This trend, then, gained momentum by Lundvall and his colleagues in the Globelics academy (Lundvall et al. 2006, 2009a). The purpose of this paper is to contribute to this strand of research. We approach the study by developing a novel method for measuring of innovation performance relevant to the context of developing countries/regions, regarding "Learning Concept". After presenting an overview of common methods, we will introduce the proposed method, and evaluate the innovation performance of different regions of Iran.

\section{Measuring of innovation performance}

There is a plethora of research on science, technology and innovation policy, which measures the innovation performance of geographical regions (Edquist, Zabala 2009; Fritsch, Slavtchev 2006; Broekel, Brenner 2007; Hollanders, Celikel-Esserl 2007). These studies use various methods and variables depending on the purpose of research and the approach of researchers with regard to the innovation concept. Suffice it to say that the selection of proxy variables and the way they are composited in the innovation measures and how their claim of coordination with the innovation style in the developing countries is redeemed, are all influenced by the researcher's approach to the definition of the concept of innovation. The method and the selection of the proxy variables these studies use could vary according to the definition of the key concept of "innovation" in the study and the goal the researcher sets. 


\subsection{Ambiguity in the concept of innovation}

While researchers have agreed on the usefulness and importance of innovation in the development of countries, there are different definitions of innovation in the literature and it is not clear how to choose among them. A narrow approach to the innovation concept has been highly regarded over the years and has many advocates especially among policy makers, because of its simplicity and ease of measurement (Caraça et al. 2009). In this approach which is rooted in the innovation behaviour of large and international firms, the innovation process is "the process of discovery" (Smith 2000) of new scientific or technological rules. In this view, innovation is a concept equivalent to science and technology and deals with "creation of formal knowledge" which is usually the result of research in R\&D departments of large manufacturing firms, public labs, research institutes, and universities. The narrow approach has some proponents in both linear and systemic paradigms of the innovation process, and fits well with behavioural features of innovation in developed countries, where radical innovations have a significant impact on economic growth.

In contrast to the above approach, there is a broad approach to the innovation concept, which is rooted in the views of Joseph Schumpeter (1934). In Schumpeterian view, a new technological change is considered as innovation when it leads to a new economic value added. Innovation not only is the middle link between research and technological change and market, but also might appear in management and organizing or marketing methods when they create new economic values.

Suffice it to say that while many scientific endowers have created new knowledge conveying scientific values, they have not necessarily led to new economic value ${ }^{1}$. That is why the meaning of "innovation" in the course of conceptualization is gradually broadening, moving away from science and technology concepts. In the 2005 version of the Oslo Manual (OECD 2005), "innovation" has a broad definition similar to Schumpeter's interpretation. As described in this manual, the meaning of "local newness" is not simply "novelty" in the world, but also includes "new for the firm or the market of the firm". Obviously, such a broad definition of innovation increases the innovative community size and makes it difficult to measure the innovation performance in geographic areas (OECD 2005).

In any case, most definitions of innovation whether be under the influence of the linear and narrow approach or the systemic and broad one, all emphasize on "newness" and "applying knowledge". In both approaches, "knowledge" is the primary input of innovation, but what is not agreed upon is the "nature of knowledge". In the broad systemic view, knowledge used in innovation may be the result of a formal process such as R\&D activities, or from experiences in the local context and interactive learning over centuries (Kraemer-Mbula, Wamae 2010). Therefore, it may be coded and explicit knowledge transferable through different channels or implicit which could be transferred only by face-to-face interactions. In the innovation literature, the first type of knowledge has significant applications in the Science-Technology-Innovation (STI) style of innovation, which is dominant pattern in developed countries, while the second type has significant

\footnotetext{
1 We are not denying their potential economic value in future since every scientific advance has the potential for subsequent developments by high economic values.
} 
applications in the Doing-Using-Interacting (DUI) style of innovation, prevalent in small or developing countries (Jensen et al. 2007). In the broad systemic view, innovation is a ubiquitous phenomenon. It is present everywhere, even in traditional sectors and not confined to high technology sectors.

Efforts to conceptualize the "innovation" have already been running into trouble because of its ambiguity, and scholars see themselves in need of using proxy variables instead. The first influential measurement of research activities is addressed to Bernal in the 1930's (Caraça et al. 2009). He measured R\&D as a proportion of GNP in the UK and advocated the effect of raising this ratio on economic growth (Bernal (1939) cited in Caraça et al. (2009)). Currently, this variable, which is an input of $R \& D$ activities, is one of the most popular proxy indices in measuring the science and technology performance of countries.

With the purpose of facilitating a comparison of the innovativeness of geographical areas, some international organizations have tried to develop science, technology, and innovation measurement standards, drawing on firm surveys. Basically, the first series of these standard manuals gave attention to R\&D activities. The Frascati Manual is one of this type, which was designed in 1962 in Europe (OECD 1962). The first editions of this manual gave attention only to formal R\&D activities, but in the sixth edition (OECD 2002), informal and occasional $\mathrm{R} \& \mathrm{D}$ activities are calculated too.

The OECD Patent Manual (OECD 2009), Okubo Report (Okubo 1997), Canberra Manual (OECD 1995) and TBP Manual (OECD 1990) are some of the other standard manuals developed by OECD for measuring science and technology creation activities in the firms. Also, UNESCO has provided similar manuals and recommendations (UNESCO 1968, 1980, 1978). Unlike the indices of $R \& D$, there is not agreement about innovation indices (Gault 2007). The Oslo Manual was designed to measure innovation activities in the firms, but underwent many changes over time. In first editions of this manual, the narrow approach to innovation was dominant, where only product and process innovations were considered and R\&D activities were emphasized as the major input of innovation (Salazar, Holbrook 2003). However, in the last edition, the Oslo Manual used the broad definition of innovation (OECD 2005). Many countries develop and implement surveys based on this manual (e.g. Community Innovation Surveys CIS). There have been other efforts to create innovation indices such as the European Innovation Scoreboard (EIS), the index of the Massachusetts Innovation Economy, the Global Innovation Index and the Nordic Innovation Monitor, which are still not as popular as Oslo Manual.

\subsection{Approaches to innovation performance of geographical areas}

Similar to "innovation", the "innovation performance" of geographical areas differs in meaning among researchers. A great number of studies use the metaphor of the geographical area as a firm for simplification and interpret "the innovation process as a product process" (Broekel, Brenner 2007), in which there are some mechanisms for converting inputs to outputs. Some scholars measure a geographical area's innovation performance from an output standpoint (Edquist, Zabala 2009) and some others use efficiency concept and count inputs, in addition to outputs (Zabala-Iturriagagoitia 2008; Fritsch, Slavtchev 2007). And finally, some scholars adhere to the 
"functional ability of the innovation system" (Carlsson et al. 2002) and measure innovation performance based on how the entire innovation system can respond to its different functions (Edquist, Hommen 2008). These studies have mostly been conducted at a national level.

It should be noted that in policy studies, innovative process outcomes and consequences, though not more valuable than, are equally considered as direct outputs. Measuring performance of innovation in areas is much harder than firms, since geographical areas are not integrated systems. The value-added of $\mathrm{R} \& \mathrm{D}$ activities or export of high-tech products are some of the output proxy variables, counted in the metaphoric approach to regions as firms with the goal of maximizing profits (economic growth).

Broekel and Brenner (2007) have reminded us about the stochastic nature of the innovation process which is in contrast to the deterministic nature of the production process. Furthermore, they have noted that managers take control over the resources of the firm except external factors (Brenner, Broekel 2009), whereas, policy makers and economic actors have extremely little effective control on regional innovativeness factors. Broekel and Bernner have divided these factors into three categories; fixed and population characteristics, policy settings, and economic activities. Fixed characteristics of a geographical area do not change significantly over time but influence other factors. The rest influence each other. However, the time scale of changes of each one is different (Broekel, Brenner 2007; Brenner, Broekel 2009). Some examples of fixed characteristics of a region include the geographic profile, geographic location and natural resources, which directly determine the regional industry structure and impact on attractiveness of the region, population, and economic characteristics, so, indirectly could influence policy decisions. Culture, believes and values are other examples of regional population characteristics which influence other attributes, especially quality of social relationships that could influence economic features and implementation of policies.

Given the above points, measuring innovation performance based only on comparing and analysing indices suggested in standard manuals, without sufficient attention to the geographical area's characteristics and the indices' suitability, could mislead policymakers and making them design policies with negative impacts on communities.

Therefore, during the process of benchmarking, one should attempt to classify geographical areas based on their corresponding features and one of the most common categories in such benchmarks is the degree of development of a country. Some of these studies, which especially contain best practices, were confided to developed or at most recently industrialized countries, not the developing ones. However, the arguments about the necessity to have a different approach to study of innovation systems of developing countries have been growing recently (Oyelaran-Oyeyinka, Rasiah 2009; Lundvall et al. 2009a; Krammer 2009), since these countries (and regions inside them) have quite different features from developed ones, which should be considered in evaluating their innovation performance and in analysing the results.

\section{Innovation features in developing countries}

Developing countries face enormous challenges, including macroeconomic uncertainty, poor physical infrastructure, institutional thickness, lack of access to new technologies and knowledge and information sources, lack of demand for innovations, lack of entrepreneurial 
and skilled manpower, financial constraints and many other obstacles which hinder the innovation process (OECD 2005; Chaminade et al. 2009; Oyelaran-Oyeyinka, Sampath 2006; Hadjimanolis 1999). Srinivas and Sutz (2005) have pointed to those challenges as scarcity conditions. Moreover, in some developing countries, especially Middle Eastern, the economies are affected by the abundance of highly valued strategic natural resources (e.g. petroleum). This kind of abundance has initiated and maintained rents and rent-seeking behaviour. This case along with a weak institutional system has created the "resource curse" phenomenon (Weinthal, Loung 2006) which disorder economic growth (Auty 1993; Gylfason 2001). Actors in the rentier economy prefer to abuse the poor institution settings and capture high incomes by means of rents than productive activities (Weinthal, Loung 2006). Rentier state (Mahdavy 1970) and political instability are some other features of such economies. Political instability reduces political-business cycles and creates severe crisis for a rentier economy (Gorgi, Eghbali 2011). A high risk of business added to rent-seeking behaviour of economic actors eliminates incentives of investment and innovation in the private sector (Miremadi 2012).

We can outline some of inconsistencies of common innovation measures with innovation features in developing countries as follows (keeping in mind that the phenomenon of "rentier economy" exacerbates all these characteristics):

- The innovation organizational setting of most firms in developing countries, which typically are small and medium firms, is informal while formal R\&D projects which are highly valued in the common innovation performance measures, are scant (Salazar, Holbrook 2003);

- Traditional sectors are responsible for the major part of wealth creation and economic development in developing countries, while common innovation indices have a structural bias to new technologies and depending on them makespolicymakers underestimate the innovation capabilities of traditional sectors (Salazar, Holbrook 2003);

- Firms inherently are risk averse. Hence, to reduce risk, they are not prone to take big steps and do radical changes and their innovations usually appear as incremental improvements and small changes, which common innovation performance measures ignore them;

- Common innovation performance measures have a strong emphasis on the private sector whose role in developing countries is negligible contrary to the main role that government plays in funding research and development and financing knowledge creation activities;

- A significant part of developing economies are based on informal activities (Chaminade et al. 2009) restraining our understanding of behaviour and performance of innovation based on the use of formal statistics;

- Innovation systems in developing countries are weak, and links are fragmented (Edquist, Chaminade 2006). This makes firms unable to overcome the technical problems, so they turn to solutions such as importing technology. In other words, "knowledge diffusion" (Arundel 2006) in developing countries usually is non-interactive (e.g. purchasing machinery and equipment, using open and freely available sources, 
especially local cases). Recent measures emphasize active knowledge diffusion (by means of collaboration) because of the importance of interactive learning;

- In most developing countries, product differentiation is captured due to low cost resources (e.g. oil, human capital) (Altenburg 2006). Hence, there is little incentive for technological innovation for differentiation making. Whereas, common innovation performance measures focus on technological innovation.

Obviously, the differences of innovation features in developing countries compared to developed ones cause differences in priorities and the methodology of innovation performance measures. None of the standard innovation performance manuals, even Oslo Manual which is the most favourite one in developing countries, has accounted those differences. Hence, Latin-American experts have suggested an annex to Oslo Manual, based on Bogota Manual, to adapt it by innovation behaviours in developing countries (Lugones, Peirano 2004). Cognizant to the substantial differences between developed and developing countries, the Bogota Manual has succeeded to draw attentions to the innovation process and the firms' capabilities in developing countries. However, since it normally relies on extensive, expensive and time consuming surveys at firm level, some developing countries have hesitated to put it in their policy making agenda, thus far despite its inherent values. Therefore, there is still a need to have an alternative measure for innovation suitable for developing countries.

This paper introduces an alternative and claims its suggested method is more practical than Bogota manual for developing countries, since by drawing on the second hand generalized data, it does not require a complicated and expensive process of collecting data and survey.

\section{Design and method}

Selecting the measures that are directly related to the expectations of a policymaker about the function of the innovation system leads to effective decisions. First of all we should mention about a fundamental difference between the goals of innovation policy research in these countries from developed ones. "Innovation system" in developed countries is an ex-post concept, while in developing countries it is an ex-ante phenomenon (Lundvall 2005). In developed countries, these systems are relatively strong, well-functioning, coherent, diversified and have spontaneously developed and matured over time. In these countries, the purpose of the study of innovation systems is maintaining or capturing the position of technology leader. Contrarily, in developing countries, in which the innovation system is still emerging, the task of system design is inevitably oriented towards the goal of socioeconomic development because all the greatest challenges in developing countries have development nature; the lack of acceptable economic performance, social and economic inequality and poverty of a significant part of the population (Lundvall et al. 2009b; Fagerberg, Verspagen 2002).

There are many controversies about the reasons of the low capability of developing countries to create new technologies. Capturing, adopting and imitating technologies, which are in the grasp and control of technology leaders, are vital means of development (Lall, Teubal 1998). Moreover, Lundvall (2011) reminds:

"The intention of the original innovation system concepts was to link innovation to economic performance and to the potential for 'catching-up' among less developed countries." 
On the base of those arguments, we claim that in developing countries, policymakers' interest in the innovation system is to understand how to catch-up the frontiers (not necessarily the international ones). Inequality and learning are two basic concepts embedded in catch-up. Catch-up means trying to compensate the lagging behind, as well as socio-economical gaps including learning inequality which leads to income inequality, by learning from frontiers. Catch-up is not pure imitation of technologies. Technologies should be adopted by users and adapted to new conditions (e.g. scarcity of skills, materials, etc.). Hence, catching-up usually involves some technological changes, small innovations, training the workers and users and enhancing innovation capability of firm through the process of the embedded learning. Learning in catching-up process occurs in different ways, from purchasing new equipment and using proper foreign new technologies, to imitation by reverse engineering techniques or designing for problem solving due to challenges of scarcity conditions (Srinivas, Sutz 2005) even reinventing the wheel. Catch-up learning leads to enhancement of firm's innovation capacity, reduce its technology gap, and empower their employees. A developing country/ region can create new transitional paths to development if there is necessary leverage as history witnesses.

Another feature of the innovation process in developing countries, which we consider in designing of proper measure, is the dominant style of innovation. In the related literature, STI and DUI are two styles of learning and innovation; the former is crucial in high technology firms (science-based innovation) and the latter is paramount in medium and low technology firms (experiment-based innovation) (Hirsch-Kreinsen et al. 2005). STI and DUI styles are complementary and exist in both developed and developing countries, with differences in intensities. Obviously, the dominant style of innovation in developing countries is DUI, since their industrial structure is largely based on medium and low technology firms rather than high-tech firms (Lundvall et al. 2009a).

And finally, the process of development in developing countries in general, is hindered by some factors, e.g. inequality in learning and consequently in revenues at interregional and domestic levels as well as international level. In other words, development in these economies is uneven. As we might know, the phenomenon of economic inequality has been the focus of numerous studies for years but there are not many studies on inequality in learning capabilities which happens to be the cause of economic inequalities. However, measuring the innovation performance in the regional level highlights the importance of attention to uneven level of (technological) learning among the different regions in a developing country.

Based on above arguments, the rate of success of a geographic area in improvement of its technology level (reducing its national/international technology gap), via both STI and DUI styles of learning, could be an appropriate proxy for the innovation performance of that region. We propose to use a composite measure with three dimensions: "learning", "catch-up", and "research and development (R\&D) efforts". None of them can be measured directly. Some scholars have used the productivity concept (total factor or labour productivity) to measure the technology gap (Sjöholm 1997; Lee 2001) as a proxy of catch-up. Improving productivity for achieving better performance levels represents some success in catch-up. Growth of productivity is a sign of learning, absorptive capacity, and innovation, more than technology transfer. In addition to product and process innovation, organizational innovations (e.g. modification of 
organizational structure or management solutions that improve efficiency or organizational climate), marketing innovations (market expansion, accessing new markets and more effective use of production capacity) and even using new materials and resources, all can increase productivity. Hence, "productivity" can be considered as an appropriate conceptual tool to measure innovation in developing regions and in different sectors as manufacturing, agriculture or services. Of course, as productivity level depends on the sectors of industries, the type of industries should be controlled in the measurement. For example high technology industries, as well as some natural-resource-based industries, such as petroleum industries, essentially have much higher levels of productivity than traditional ones. That means productivity level is industry-specific. The impact of fixed characteristics of a geographical area can be better understood now. Natural resources, climate, and geographical factors significantly influence (sometimes determine) the industrial structure of a region and thus its productivity level. We can control this effect by measuring the technology gap with respect to the "field of industrial activity" in each region.

The industry structure of developing countries is bipolar (Lavopa, Szirmai 2011; Altenburg 2009). In these countries, a small fraction of this structure consists of large and high productivity firms, while the bigger section contains lots of small and micro firms with very low productivity levels and barely increasing performance (Altenburg 2009). Lavopa and Szirmai (2011) have named this phenomenon as "partial catch-up". They recognize the stylized patterns of developing countries structure in an empirical study. According to these patterns, the distribution of industrial sectors, according to their distance to technology leaders, expands during developing process and moves from the extreme pattern of a lagged economy to the extreme pattern of a developed one (Fig. 1) and transit from the middle bipolar structure. In extreme patterns, most sectors lie in the same range of technology gap.
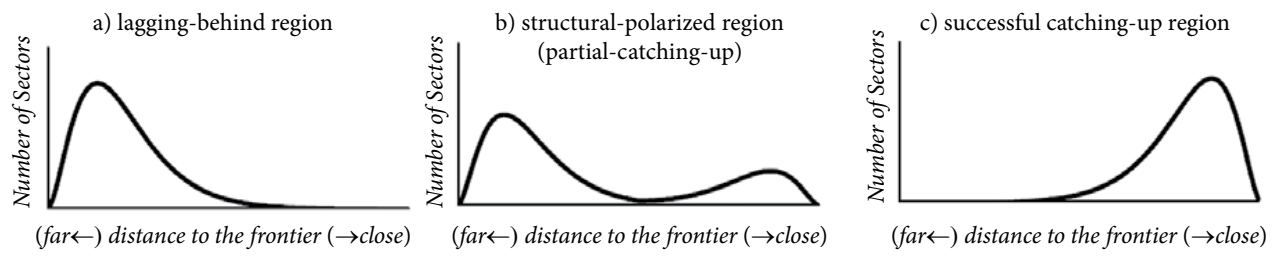

Fig. 1. Theoretical patterns of the distribution of sectors according to their technological gap Source: (Lavopa, Szirmai 2011) reproduced with permission from authors.

We can use these theoretical patterns (we call them "catch-up patterns") in the process of measuring and interpretation of the innovation performance of developing regions. Lavopa and Szirmai have used the measure of distribution of sectors to evaluate the compliance of the industrial structure of countries with these patterns, but this method is not suitable for constructing an innovation performance measure. First, it is not straightforward and requires intuitive judgment. For example, as Lavopa and Szirmai measure, the distribution of sectors of Mexico, similar to the Republic of Korea, was decreased over time after experiencing a bipolar structure pattern. Unlike Korea, this was not a sign of Mexico's success; in contrast, the catch-up pattern of Mexico has a backward to a lagging-behind (Fig. 2). It means that 

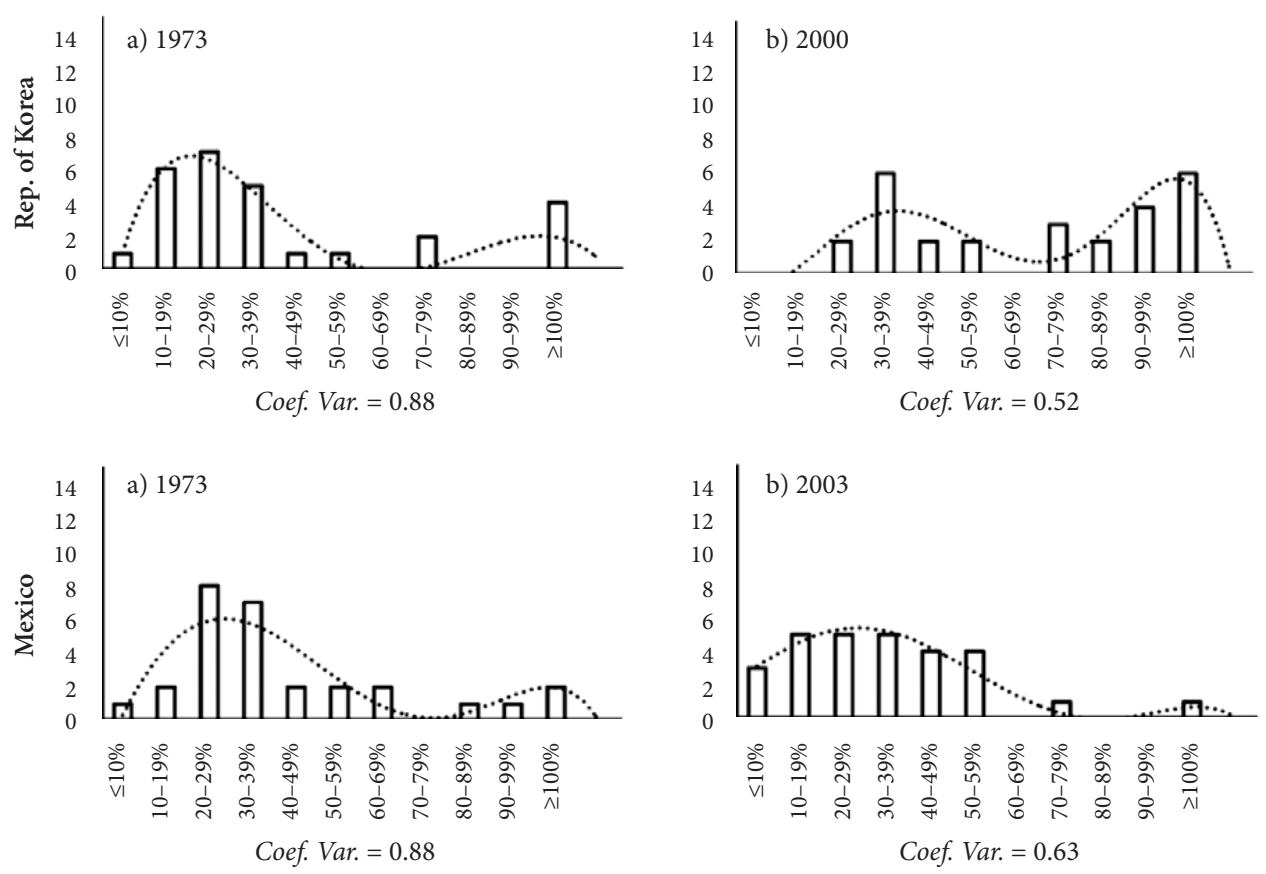

Fig. 2. Distribution of sectors by labor productivity in the Rep. of Korea and Mexico Source: (Lavopa, Szirmai 2011) reproduced with permission from authors.

industrial sectors of this country haven't learned enough to close their technology gap and their gap has increased over time. Secondly, the vertical axes of patterns represent "the number of sectors", and their size and importance in the development of economies are ignored. Consider the case of the existence of a lot of small low-productivity sectors, which have no significant role in the development of the region, while some limited high-productivity sectors make contribute greatly to the employment and wealth of it (e.g. industrial cluster). The catch-up pattern of such a case is close to a lagging-behind region instead of a successful catching-up one. Finally, we cannot have a proper assessment of the real behaviour of innovation in a region only with respect to its catch-up pattern in an interval of time. "Time" is a key factor. The inability of a region to reduce its technology gap in a significant period means the interactive learning in that region is not sufficient, and its innovation performance is poor. The behaviour of the region must somehow be taken into account in the innovation performance measure. Furthermore, it is necessary to know the extent of R\&D efforts in a region in order to find out how the innovation performance of the region is based on STI or DUI styles of learning.

Using the catch-up pattern to construct the catch-up index, we consider the importance of industrial sectors, instead of "number of sectors", on the vertical axis of patterns. The importance of the factor of value added of sectors in economic development is obvious. Moreover, from the learning standpoint the factor of employment in high performance 
sectors has the same importance ${ }^{2}$. Communication between workers of these sectors has a significant role in the flow of knowledge and consequently innovations and improvement of productivity. Therefore, with the assumption of reducing the technology gap as one of the most important outcomes of innovation system in developing regions, we can define the catch-up index as follows:

$$
C A T C H_{s}^{t}=\sum_{i=1}^{n}\left(\left(\frac{S H L_{i, s}^{t}+S H V_{i, s}^{t}}{2}\right) G A P I N V_{i, s}^{t}\right) ; \sum_{i=1}^{n}\left(\frac{S H L_{i, s}^{t}+S H V_{i, s}^{t}}{2}\right)=1,
$$

where: $\mathrm{CATCH}_{s}^{t}$ is catch-up index of the region $s$ at the period of $t ; n$ is the number of industrial sectors in the region $s$; $S H L_{i, s}^{t}$ is the industrial employment share of the sector $i$ at the period of $t$ in the region $s$; and $S H V_{i, s}^{t}$ is the industrial value added share of the sector $i$ at the period of $t$ in the region $s$. We consider $\left(\frac{S H L_{i, s}^{t}+S H V_{i, s}^{t}}{2}\right)$ as the importance coefficient of the technology gap of industrial sector $i$ in the region $s$ at the period $t$.

GAPINV $V_{i, s}^{t}$ is the reverse of the technology gap of the industry sector $i$ from the sector's leader at the period of $t$, which measures as follows:

$$
G A P I N V_{i s}^{t}=\frac{P_{i, s}^{t}}{\max \left(P_{i}^{t}\right)}=\frac{\frac{V_{i, s}^{t}}{L_{i, s}^{t}}}{\max \left(\frac{V_{i}^{t}}{L_{i}^{t}}\right)},
$$

where: $P_{i, s}^{t}$ is the labor productivity of the sector $i$ in the region $s$ at the period of $t$; and $\max \left(P_{i}^{t}\right)$ is the labour productivity of the technology leader (industry's highest productivity). Labour productivity is simply obtained by dividing the industry's value added to the number of industry's workers.

Catch-up index gives us a picture of the whole industrial productivity of a region at a certain section of time, and its change over time could be a proxy for the learning of the region:

$$
\operatorname{LRN}_{s}^{t}=C A T C H_{s}^{t}-C A T C H_{s}^{t-1}
$$

where: $L R N_{s}^{t}$ is the learning index of the region $s$ at the period of $t$.

In order to complement our understanding of innovation behaviour of regions, it is necessary to consider R\&D efforts of the region in addition of catch-up and learning indices. Geographical areas have different behaviours; for example, some regions with high performance and success in catch-up are not continuing to learn further and so are in danger of decline because of various system failures such as "lock-in". Some other regions are close to a lagging-behind pattern, but their conditions have started to improve lately improving because of learning incentive policies. On the other hand, some regions have allocated noticeable resources to R\&D efforts and achieved some success in the past but now they are not

2 Obviously, we can designate different weights to different sectors of activities, based on policymaker viewpoints, e.g. higher weight to ICT or High-Tech sectors, which are distinguished as crucial sectors to development. 
continuing their efforts in catching-up because of deep knowledge gap between industries and research institutions or weak networks. It is clear that different regions require different and specific policies to enhance innovation performance. The amount of reported innovations (e.g. the number of patents per one million populations or other similar national statistics) can be used as a proper proxy of R\&D efforts.

By using the suggested compound measure, we can recognize if a province has better achievement and learned more along the time compared to others. Using the fuzzy set theory (Zadeh 1965) allows us a better comparison between regions. We have used the method in a comparative analysis of provinces of Iran.

\section{Case of Iran's provinces}

Iran is a vast country and has a great diversity of climate, ethnicity, and culture. Its economy is dependent on natural resources, especially petroleum and has rentier property (Mahdavy 1970; Gorgi, Eghbali 2011; Miremadi 2012; Ghazinoory, Ghazinouri 2009). These make for different economic and social attributes and consequently an income inequality and enormous gap in the development level between its provinces. Innovation policy decisions are mainly taken by the central government, but significant regional differences point to the necessity of provincial (regional) policy making based on the study of innovation behaviour and performance of provinces to reduce their gaps and balance economic development. In this study, we have measured the innovation performance of the manufacturing sectors in 29 provinces of Iran, using their experimental catch-up patterns in two 4-year periods of 2000-2003 and 2004-2007. We have used the average values of variables in each period to eliminate short-run instabilities. Throughout this study, we have used published regional data from Statistical Centre of Iran.

Some studies tend to measure the technology gap of a country with a global technology leader (e.g. USA) (Lavopa, Szirmai 2011). Nevertheless, firms use at first their existing knowledge base to do innovation and only if it is insufficient; seek new sources. Furthermore, for learning from technology frontiers, firms should have some capability and cognitive proximity with frontiers. Distance from the source of knowledge (geographical proximity) is also effective in doing innovation (Cohen, Morrison Paul 2009; Boschma 2005), especially when knowledge flow tends to be limited in regions, because of its tacit aspect (Jaffe et al. 1993). In developing countries, where linking via the global knowledge network can be difficult for various reasons including limitations of language, naturally, the most influential source of knowledge of the firms are the domestic or national suppliers, customers, and competitors. In Iran, in particular, some factors such as trade sanctions have escalated this rupture. Hence, the attempt of each province to reduce their technology gap with other provinces can also be considered as an indication of its learning and a proxy for its innovation performance. Obviously, a region that has links to foreign networks of knowledge can faster reduce its technology gaps, and in the case of the technology leader of the country, can also maintain its position.

Remembering the industry-specific aspect of productivity, we have provided an experimental catch-up pattern and have measured the catch-up index of each province, as a weighted sum of the technology gap of each manufacturing activity in the province with respect to a 
province, which is the leader of the activity in the country. Using Eq. (1) in two 4-year-periods, we have calculated the learning and catch-up and indices of each province. We have used the number of formally reported inventions/innovations per one million populations as a proxy of $R \& D$ efforts of provinces.

Appendix-A provides measures of the learning, catch-up and R\&D effort indices of all 29 provinces of Iran. There are also illustrated the experimental catch-up patterns of provinces in two periods. Using these measures, we can understand if a province had a better outcome and learned more compared to others, but we cannot easily infer from it how the provinces can be considered innovative. We have used the fuzzy set theory (Zadeh 1965), suggested by Ragin (2008) for a better comparison. In this approach, measures should be interpreted. The raw measures are uncalibrated. They become calibrated by interpreting, meaning transforming them to sets. The interpretation is affected by existing and substantial knowledge. As we will show, the provinces are more or less learning, catching-up, and have accomplished some achievements in R\&D. On the other words, each province has a degree of membership in "learning regions set" $(L)$, a degree of membership in "catching-up regions set" $(C)$ and a degree of membership in "research-developing regions set" $(R D)$. We have used direct calibration procedure, using log-odds suggested by Ragin (2008). Fuzzy membership function is defined as follows:

$$
\mu(x)=\frac{1}{1+e^{-a(x-b)}} .
$$

For using this technique, we should specify three qualitative anchors for each set to distinguish between innovative and non-innovative provinces. Those are $x_{h}$ as full membership threshold (with fuzzy membership score $\mu_{h}=0.95$ ) $x_{l}$ as non-membership threshold (with fuzzy membership score $\mu_{l}=0.05$ and $b$ as crossover or maximum ambiguity breakpoint (with fuzzy membership score $\mu_{c}=0.5$, then we use two different $a$ to calculate fuzzy memberships, $a_{h}$ for $x>b$ and $a_{l}$ for $x<b$ :

$$
a_{h}=\frac{\ln \left(\frac{\mu_{h}}{1-\mu_{h}}\right)-\ln \left(\frac{\mu_{c}}{1-\mu_{c}}\right)}{x_{h}-b} ; a_{l}=\frac{\ln \left(\frac{\mu_{c}}{1-\mu_{c}}\right)-\ln \left(\frac{\mu_{l}}{1-\mu_{l}}\right)}{x_{h}-b} .
$$

Selection of qualitative anchors should be based on theoretical issues and cases attributes. We recognize the similarity of experimental catch-up patterns of the provinces by a catch-up index close to 0.6 or larger, to theoretical successful catching-up pattern (Fig. 1) and those by a catch-up index close to 0.3 or smaller, to theoretical lagging-behind pattern. Hence, we have selected qualitative anchors of catching-up regions set $(C)$ as follows:

Threshold of full membership: $0.6 \quad$ Threshold of full non-membership: 0.3

Maximum ambiguity: 0.5

That means, regions by catch-up index less than 0.3 are categorically lagging-behind; regions by catch-up index more than 0.6 are catching-up (fully in catching-up regions set); regions by catch-up index between 0.5 and 0.6 are in transition but they are near to success (more in than out of the catching-up regions set); and regions by catch-up index between 0.3 and 0.5 are in transition but near to the set of lagged-behind (more out than in 
the catching-up regions set). As the same order, the anchors of learning regions set $(L)$ are respectively selected as $0.2,-0.1$ and 0 . Finally, the anchors of research-developing regions set $(R D)$, are respectively selected as $125,20,50$, based on a simple clustering routines.

High outcome (success in catch-up or R\&D) signs satisfactory performance and worthy of reward, while lack of learning means malfunction of innovation system and points to existence of system failures. Using this insight, "innovative regions set" $(I)$ is the combination (logical AND) of the "learning regions set" and the union of "catching-up regions set" and "research-developing regions set". In other words, significant learning and success in catchup or research activities are counted as sufficient conditions for a region to be innovative.

$$
\begin{aligned}
& I(x)=L \cap(C \cup R D)(x) ; \\
& L \cap(C \bigcup R D)(x)=\min \{L(x),(C \bigcup R D)(x)\}, C \bigcup R D(x)=\max \{C(x), R D(x)\} .
\end{aligned}
$$

Appendix-B provides a comparison and classification of Iran's provinces and the degree of their membership in innovative, learning, catching-up and research-developing regions sets. As an example, Kerman has the full membership degree of 1 in catch-up regions set despite the full out membership degree of 0.03 in research-developing regions set, so the membership degree of Kerman in the union of these sets is 1 . In combination with the membership degree of 0.26 in learning-regions set, Kerman's membership degree in innovative regions set would be the minimum of those degrees that is 0.26 . That means Kerman is a somewhat non-innovative region. A summary of classification is provided in the Table.

Table. Innovativeness classification of Iran's provinces

\begin{tabular}{llll}
\hline Innovative & Somewhat innovative & Somewhat non-innovative & Non-innovative \\
\hline Tehran & Isfahan & Fars & Kohgilouye-Boir-Ahmad \\
& Zanjan & Guilan & Hormozgan \\
& Mazandaran & Khuzestan & Golestan $^{*}$ \\
& Boushehr & West-Azerbaijan & Chaharmahal-Bakhtiari \\
& & Ghazvin & South-Khorasan \\
& Markazi & Ardebil \\
& Kerman & North-Khorasan \\
& Semnan & Kurdistan \\
& Kermanshah & \\
& Hamedan & \\
& Razavi-Khorasan & \\
& Qom & \\
& Yazd & \\
& Lorestan & \\
& East-Azerbaijan & \\
& Sistan - Baluchistan &
\end{tabular}

${ }^{*}$ High score in catch-up index with serious risk of decline due to insufficient learning.

As the Table shows, only Tehran province is recognized as an innovative region, and four other provinces are somewhat innovative by membership degree greater than 0.5 in innovate regions set. That means between 29 provinces of Iran, regional innovation systems of 24 provinces have serious failures which policymakers should recognize and decide how to remove them by more studies. Characteristics of the members of each class are not similar. 
That means there are different paths to success/failure. For example, most of the "somewhat innovative regions" are industrial, except Mazandran which has an agricultural-based economy. On the contrary, most of the "somewhat non-innovative regions" are agricultural and have traditional and low technology manufacturing sectors and suffer from low income, and other inequalities. Beside them, we can see some industrial provinces by large manufacturing firms and universities, which are unable to use their valuable knowledge resources. Furthermore, as in the Table and Appendix B, most of the provinces by high membership degree in research-developing regions set are (somewhat) non-innovative. It could be the case as due of the improper science and technology policies or large cognitive/knowledge gap between research institutes and manufacturing firms. Almost all of the (somewhat) innovative provinces have low formal research achievements, which supports the argument about the importance of DUI-based style of learning in developing countries (Hirsch-Kreinsen et al. 2005).

For assessing the criterion validity of measure (Šaparauskas et al. 2011), the provincial GDP (without oil revenue) per head has been used. It is expected that the provinces recognized as innovators have upper GDP per capita. The existence of positive and meaningful correlation of Pearson among the degree of the provinces' membership in innovative regions and the provincial GDP per capita supports the criterion validity of the measurement $(r=0.606, \rho=0.000)$.

Fig. 3 provides catch-up patterns of four provinces by different characteristics at two periods.

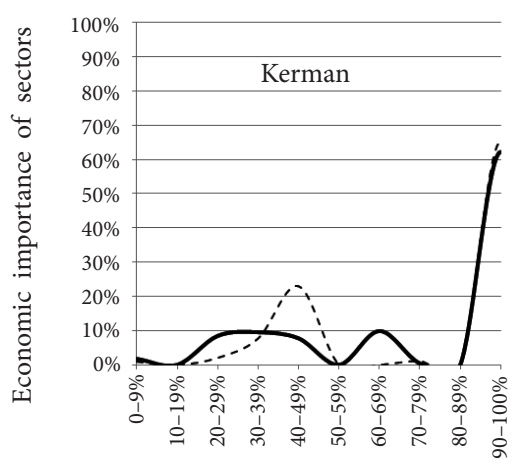

(reverse) Techology gap

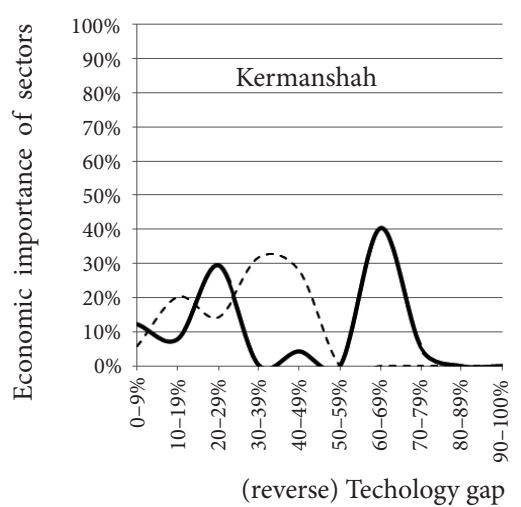

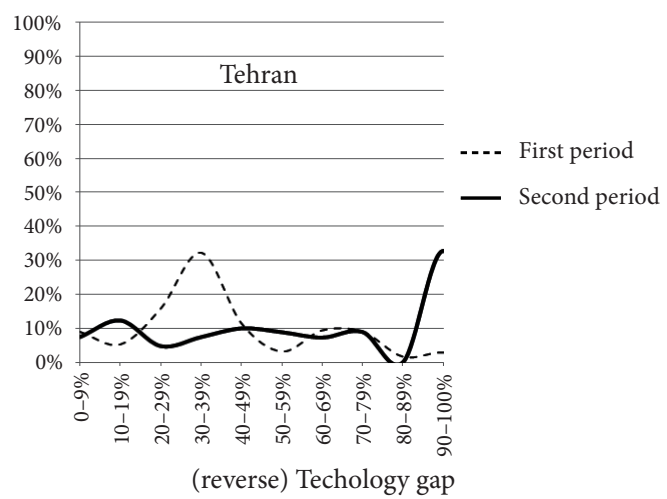

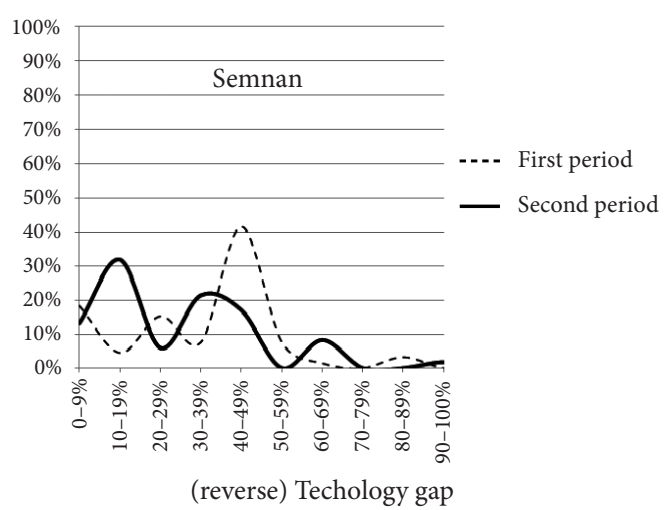

Fig. 3. Experimental catch-up patterns of four developing regions in Iran 
Tehran province includes the metropolis of Tehran (capital of Iran) and has a financial service-based economy. Tehran also has the highest diversity in manufacturing activities in the country and benefit from existence of large universities and research institutes, large population of elites, and a relative abundance of financial resources. Tehran is recognized as the unique innovative region in our study, but as can be seen in Fig. 3, it was not a country technology frontier in almost any industry sectors in the first period of study, contrary to public perception. Nevertheless, it has experienced significant learning and could greatly reduce the technology gap between the most of its manufacturing sectors and national technology frontiers in the second period of the study, Tehran is the country technology leader in some of manufacturing sectors which provide near one third of employment and value added of the province in the second period, despite insufficient formal research efforts of firms.

In contrast to Tehran, Kerman, which has fully membership in catching-up regions set, does not have diversity in manufacturing activities. Its economy is mineral-resource-based, and manufacturing of basic metals (copper) is the dominant industrial sector in this province. Firms of this sector are often large and essentially have high productivity. It can be argued that Kerman is a professional region and benefits from the feature of the national frontier in the basic metals sector. However, Kerman has not continued learning long enough during the periods of study, and despite maintaining its leadership position in its professional activities it shows a little decrease in its catch-up index (Fig. 3). This could be an alarm to policymakers about Kerman's system failure of "locking" in existing knowledge and consequently failure of the innovation system of this region.

Policymakers can recognize regions with high learning potential, based on the information provided by the Appendices. Then, they can apply appropriate policies and reduce barriers of catch-up and R\&D efforts in such regions. For example, in the periods of study, Kermanshah has learned much but it has not succeeded in catch-up and R\&D. If we observe its catch-up pattern, we can see that it has moved from a lagging-behind profile to a structural bipolar one (Fig. 3). Moreover, the bipolarity of this province is specific: the dominant pole consists of more productive sectors. This remarkable behaviour deserves more attention of policymakers and deeper study about the obstacles to innovation and development in this province. While Kermanshah is a less-developed region because of a weak manufacturing infrastructure, science and technology policymakers have not much attention to it. Public expenditure in $\mathrm{R} \& \mathrm{D}$ is less than the average of the country and has been reducing over time.

The province of Semnan's status is the opposite of Kermanshah. It is an industrial province with a fully membership degree in research-developing regions set. Semnan's public expenditure in $R \& D$ in the periods of study is more than twice the national average; invention per capita is four times the national average and has a significant rate of literacy and graduate manpower. However, the experimental catch-up pattern of Semnan presents lack of learning, enlarging technology gap of manufacturing sectors and backward to lagging-behind situation (Fig. 3). While statistics indicate a significant increase in the number of manufacturing firms and diversification of industrial sectors in Semnan, it seems that inappropriate supportive policies serve to reinforce the traditional and non-productive sectors, which cannot properly link with the centres of knowledge creation in this province. In our classification, Semnan is recognized as a non-innovative province (Table). 


\section{Summary and conclusion}

Measuring innovation performance of geographical areas is essential to attain the aims of policymaking. This importance is not confined to the national level. In the case of vast countries such as Iran, which encompasses varieties of climate and culture and the economic progress has exacerbated the uneven development of the different regions, measuring the innovation performance at the regional level is extremely useful. Common innovation measures derive from the dominant innovation behaviour in developed countries and are appropriate to the objectives and functions of their sound and coherent innovation systems but are not suitable for use in developing countries.

The behaviour and style of innovation in developing countries is affected by economic structure and its attributes. High-technology firms make up a small fraction of the economic value of developing countries. On the other hand, the medium and low technology firms in these countries, which are normally ignored by common innovation measures, are the driver of the national economic growth. That is partially the reason why these firms often do not benefit from science, technology, and innovation policies and do not benefit from as many opportunities as they deserve. Moreover, although innovation should be regarded present in all economic sectors, common measures target a specific style of innovation (STI mode), so they are unable to show the real picture of the innovation behaviour in developing regions to policymakers. The dominant style of innovation in developing areas is DUI, which relies on existing knowledge and experience. In these countries, innovations are incremental, and changes are minor. Diffusion of knowledge, imitation, and learning obtained from it in a "scarcity conditions" is more urgent than knowledge creation. Tracking and measuring innovation process output is difficult, due to the nature of innovation in these countries. Therefore, the only effective way to measure is tracking outcomes of innovation and using proxy variables to measure its performance.

One of the main reasons for the policymakers of developing countries to study innovation systems is to understand how to design a catch-up strategy for their economies. Catch-up here means learning from regional/national/international frontiers and reducing learning inequality in order to diminish income inequality. By this approach, we claim that the main function of innovation systems in developing countries is closing the technology gap with the leaders, so this concept can be a relevant and appropriate proxy for measuring innovation performance in these countries. The success of a developing region in catch-up is an important criterion for its innovation system performance. We believe the experimental catch-up pattern, which the productivity concept is used as its proxy in this paper, is an effective way to understand the innovation behaviour of a developing region. Nevertheless, if the policymaker doesn't pay attention to the changes of patterns over time, his understanding of regional performance will be incomplete and in some cases, even misleading. These changes show the success/failure of the geographical area in learning, and allow the policymaker to search for regional factors shaping the pattern and its changes, and decide about appropriate policies to accelerate learning and catch-up.

The strength of this approach is its appropriateness to the purpose of evaluation from the policymaker's insight. However, it is case-based: the style of experimental catch-up pattern of a 
region is dependent on the selection of the technology leader region. For example, a developing region which at a national level is recognized as a successful catching-up one probably would be a partial-catching-up when it is evaluated at a global level. Similarly, changes in the anchors of fuzzy sets could cause some changes in the results.

The study of catch-up patterns of Iran's provinces and their learning behaviour shows that few of them have the proper performance. Most provinces have insufficient learning and only a few has decreased their technology gap with the sectorial-national leaders. There is no doubt that economic sanctions and reduction in international trade relationships in addition to factors such as isolation from global knowledge networks due to language and culture are highly effective in reducing learning and innovation in Iran. However, such factors are somewhat controlled in this study because we have compared regional performance within national level (but not global). Secondly, innovation-affecting policies are centrally determined in Iran, and local policies are rare. Thus, it seems that the behavioural differences between these provinces are highly influenced by fixed characteristics of regions and its consequences such as industrial structures, as well as population characteristics (social and cultural factors). This reveals the necessity of policy research using a deep case study method to understand the effective attributes of each province, which affect its innovation and learning behaviour and diagnose their specific system failures. Undesirable innovation behaviours of most of the provinces reflect the inefficiency of centralized policymaking.

Furthermore, the results of innovation performance measures in Iran reaffirm the fact that there is a chasm between the centre "Tehran" as the Capital of the country and the peripheral regions in terms of productivity and innovation. The chasm has been resulted by the consistent attention Tehran has drawn, while the remote areas and far reach regions like Kohgilouye-Boir-Ahmad and Hormozgan have lost their chances for catching up and being innovative during these years. Suffice it to say, it needs to have further study to be more specific about the inequality among the regions and the policy implications in order to ameliorate this situation.

It should be noted that we did not consider the rentier aspect of Iran's economy. Some of the superficial improvements in productivity may result from the rent-seeking behaviour of economic actors, which provides more opportunities in core areas, and may not be based on technological learning. This behavioural feature should be considered in subsequent studies.

\section{References}

Altenburg, T. 2006. Opportunities for Asian countries to catch up with knowledge-based competition, in Lundvall, B. Å.; Intarakumnerd, P.; Vang, J. (Eds.). Asia's innovation systems in transition. Cheltenham: Edward Elgar, 21-53. http://dx.doi.org/10.4337/9781847201737.00009

Altenburg, T. 2009. Building inclusive innovation systems in developing countries: challenges for IS research, in Lundvall, B. Å.; Joseph, K.; Chaminade, C.; Vang, J. (Eds.). Handbook of innovation systems and developing countries: building domestic capabilities in a global setting. Cheltenham: Edward Elgar, 33-56. http://dx.doi.org/10.4337/9781849803427.00008

Arocena, R.; Sutz, J. 1999. Looking at national innovation systems from the south, in DRUID's Summer Conference 1999, 9-12 June 1999, Rebild, Denmark.

Arundel, A. 2006. Innovation survey indicators: any progress since 1996?, in The G20 at the Leader's Level Workshop (L20 Workshop), United Nations University and the University of Maastricht, Maastricht, The Netherlands. 
Auty, R. M. 1993. Sustaining development in mineral economies: the resource curse thesis. London: Routledge, 77-78.

Bernal, J. D. 1939. The social function of science. London: Routledge and Kegan Paul. 500 p.

Boschma, R. A. 2005. Proximity and innovation: a critical assessment, Regional Studies 39(1): 61-74. http://dx.doi.org/10.1080/0034340052000320887

Brenner, T.; Broekel, T. 2009. Methodological issues in measuring innovation performance of spatial units, Working Papers on Innovation and Space. Philipps University Marburg, Marburg, Germany.

Broekel, T.; Brenner, T. 2007. Measuring regional innovativeness: a methodological discussion and an application to one German industry, in Dynamics of Knowledge Accumulation, Competitiveness, Regional Cohesion and Economic Policies. Working papers. DIME.

Caraça, J.; Lundvall, B.-Å.; Mendonça, S. 2009. The changing role of science in the innovation process: from Queen to Cinderella?, Technological Forecasting and Social Change 76(6): 861-867. http://dx.doi.org/10.1016/j.techfore.2008.08.003

Carlsson, B.; Jacobsson, S.; Holmén, M.; Rickne, A. 2002. Innovation systems: analytical and methodological issues, Research Policy 31(2): 233-245. http://dx.doi.org/10.1016/S0048-7333(01)00138-X

Chaminade, C.; Lundvall, B. Å.; Vang-Lauridsen, J.; Joseph, K. 2009. Innovation policies for development: towards a systemic experimentation based approach, in Lundvall, B.Å.; Joseph, K.; Chaminade, C.;Vang-Lauridsen, J. (Eds.). Handbook of innovation systems and developing countries. Edward Elgar, 360-379.

Cohen, J. P.; Morrison Paul, C. J. 2009. Agglomeration, productivity and regional growth: production theory approaches, in Capello, R.; Nijkamp, P. (Eds.). Handbook of regional growth and development theories. Cheltenham, UK: Edward Elgar, 101-117. http://dx.doi.org/10.4337/9781848445987.00013

Edquist, C.; Chaminade, C. 2006. Industrial policy from a systems-of-innovation perspective, EIB PAPERS 11: 108-132.

Edquist, C.; Hommen, L. 2008. Small country innovation systems: globalization, change and policy in Asia and Europe. Cheltenham, UK: Edward Elgar Publishing Limited. 560 p. http://dx.doi.org/10.4337/9781847209993

Edquist, C.; Hommen, L.; McKelvey, M. 2001. Innovation and employment: process versus product innovation. Edward Elgar Publishing Limited. 214 p.

Edquist, C.; Zabala, J. M. 2009. Outputs of innovation systems: a European perspective. Centre for Innovation, Research and Competence in the Learning Economy (CIRCLE), Lund, Sweden.

Fagerberg, J.; Verspagen, B. 2002. Technology-gaps, innovation-diffusion and transformation: an evolutionary interpretation, Research Policy 31(8-9): 1291-1304.

http://dx.doi.org/10.1016/S0048-7333(02)00064-1

Freeman, C. 2002. Continental, national and sub-national innovation systems - complementarity and economic growth, Research Policy 31(2): 191-211. http://dx.doi.org/10.1016/S0048-7333(01)00136-6

Fritsch, M.; Slavtchev, V. 2006. Measuring the efficiency of regional innovation systems - an empirical assessment, Freiberg Working Papers. Technical University of Freiberg, Freiberg, Germany.

Fritsch, M.; Slavtchev, V. 2007. What determines the efficiency of regional innovation systems?, Jena Economic Research Papers. Friedrich-Schiller-University, Max Planck Institute of Economics, Jena, Germany.

Gault, F. 2007. Science, technology and innovation indicators: the context of change, in Arundel, A.; Colecchia, A.; Gault, F. (Eds.). Science, technology and innovation indicators in a changing world: responding to policy needs. OECD.

Ghazinoory, S.; Ghazinouri, R. 2009. Nanotechnology and sociopolitical modernity in developing countries; case study of Iran, Technological and Economic Development of Economy 15(3): 395-417. http://dx.doi.org/10.3846/1392-8619.2009.15.395-417 
Gorgi, E.; Eghbali, A. R. 2011. Study of a rentier economy with an emphasis on political business cycles: a theoretical analysis, Research Letter of Political Science 6: 137-154 (in Persian).

Griliches, Z. 1979. Issues in assessing the contribution of research and development to productivity growth, in Griliches, Z. (Ed.). R\&D and productivity: the econometric evidence. University of Chicago Press, 17-45.

$\mathrm{Gu}, \mathrm{S} .1999$. Implications of national innovation systems for developing countries: managing change and complexity in economic development. UNU-INTECH, Maastricht.

Gylfason, T. 2001. Nature, power and growth, CESifo Working Paper. Center for Economic Studies \& Ifo Institute for Economic Research, Munich, Germany.

Hadjimanolis, A. 1999. Barriers to innovation for SMEs in a small less developed country (Cyprus), Technovation 19(9): 561-570. http://dx.doi.org/10.1016/S0166-4972(99)00034-6

Hirsch-Kreinsen, H.; Jacobson, D.; Laestadius, S.; Smith, K. 2005. Low and medium technology industries in the knowledge economy: the analytical issues, in Hirsch-Kreinsen, H.; Jacobson, D.; Laestadius, S. (Eds.). Low-tech innovation in the knowledge economy. Peter Lang, Frankfurt, 11-30.

Hollanders, H.; Celikel-Esserl, F. 2007. Measuring innovation efficiency, INNO Metrics 2007 report. European Commission, DG Enterprise, Brussels.

Jaffe, A. B.; Trajtenberg, M.; Henderson, R. 1993. Geographic localization of knowledge spillovers as evidenced by patent citations, Quarterly Journal of Economics 108(3): 576-598. http://dx.doi.org/10.2307/2118401

Jensen, M. B.; Johnson, B.; Lorenz, E.; Lundvall, B. Å. 2007. Forms of knowledge and modes of innovation, Research Policy 36(5): 680-693. http://dx.doi.org/10.1016/j.respol.2007.01.006

Kim, L. 1997. Imitation to innovation: the dynamics of Korea's technological learning. Harvard Business School Press. 301 p.

Kraemer-Mbula, E.; Wamae, W. 2010. Innovation and the development agenda. OECD/IDRC.

Krammer, S. M. S. 2009. Drivers of national innovation in transition: evidence from a panel of Eastern European countries, Research Policy 38(5): 845-860. http://dx.doi.org/10.1016/j.respol.2009.01.022

Lall, S.; Teubal, M. 1998. Market-stimulating technology policies in developing countries: a framework with examples from East Asia, World Development 26(8): 1369-1385.

http://dx.doi.org/10.1016/S0305-750X(98)00071-0

Lavopa, A.; Szirmai, A. 2011. The impact of sectoral heterogeneities in economic growth and catching up: empirical evidence for Latin American manufacturing industries, in 9th Globelics International Conference, 15-17 November, 2011, Buenos Aires.

Lee, J.-W. 2001. Education for technology readiness: prospects for developing countries, Journal of Human Development 2(1): 115-151. http://dx.doi.org/10.1080/14649880120050219

Lugones, G.; Peirano, F. 2004. Proposal for an annex to the Oslo manual as a guide for innovation surveys in less developed countries non-member of the OECD. RICYT, Ibero-American Network of Science and Technology Indicators.

Lundvall, B. Å. 2005. National innovation systems - analytical concept and development tool, in DRUID Tenth Anniversary Summer Conference on Dynamics of Industry and Innovation: Organizations, Networks and Systems, 2005, Copenhagen, Denmark.

Lundvall, B. Å. 2011. Notes on innovation systems and economic development, Innovation and Development 1: 25-38. http://dx.doi.org/10.1080/2157930X.2010.551064

Lundvall, B. Å.; Intarakumnerd, P.; Vang, J. 2006. Asian innovation systems in transition. Cheltenham: Edward Elgar. 336 p. http://dx.doi.org/10.4337/9781847201737

Lundvall, B. Å.; Joseph, K.; Chaminade, C.; Vang, J. 2009a. Handbook of innovation systems and developing countries: building domestic capabilities in a global setting. Cheltenham: Edward Elgar. $416 \mathrm{p}$.

http://dx.doi.org/10.4337/9781849803427 
Lundvall, B. Å.; Vang, J.; Joseph, K.; Chaminade, C. 2009b. Innovation system research and developing countries, in Lundvall, B. Å.; Joseph, K.; Chaminade, C.; Vang, J. (Eds.). Handbook of innovation systems and developing countries: building domestic capabilities in a global setting. Cheltenham: Edward Elgar, 1-32. http://dx.doi.org/10.4337/9781849803427

Mahdavy, H. 1970. The pattern and problems of economic development in rentier states: the case of Iran, in Cook, M. (Ed.). Studies in the economic history of the Middle East. London: Oxford University Press, 428-67.

Miremadi, T. 2012. The vicious circles of underdevelopment and their impacts on the national innovation system in Iran, Journal of Science and Technology Policy 5: 17-30 (in Persian).

OECD. 1962. Frascati manual, proposed standard practice for surveys on research and experimental development. Paris: OECD.

OECD. 1990. Proposed standard method of compiling and interpreting technology balance of payments data: tbp manual 1990, The Measurement of Scientific and Technological Activities Series. Paris: OECD.

OECD. 1995. The measurement of scientific and technological activities. manual on the measurement of human resources devoted to $S \& T$. 'Canberra manual'. Brussels, Luxembourg: OECD and ECSC-EC-EAEC.

OECD. 2002. Frascati manual, proposed standard practice for surveys on research and experimental development. Paris: OECD.

OECD. 2005. Oslo manual: guidlines for collecting and interpreting innovation data, the measurement of scientific and technological activities. Paris: OECD.

OECD. 2009. OECD patent manual. Paris: OECD.

Okubo, Y. 1997. Bibliometric indicators and analysis of research systems, methods and examples, STI Working Paper. Paris: OECD.

Oyelaran-Oyeyinka, B.; Rasiah, R. 2009. Uneven paths of development: innovation and learning in Asia and Africa. Cheltenham: Edward Elgar Publishing Limited. 256 p. http://dx.doi.org/10.4337/9781848446144

Oyelaran-Oyeyinka, B.; Sampath, P. G. 2006. Rough road to market: institutional barriers to innovations in Africa, Working Paper Series. UNU-Merit, Maastricht, The Netherlands.

Ragin, C. C. 2008. Redesigning social inquiry: fuzzy sets and beyond. Chicago, USA: University of Chicago Press. 234 p. http://dx.doi.org/10.7208/chicago/9780226702797.001.0001

Salazar, M.; Holbrook, A. 2003. A debate on innovation surveys, in Conference in Honour of Keith Pavitt "What do we know about innovation?", 2003, SPRU, University of Sussex.

Šaparauskas, J.; Zavadskas, E. K.; Turskis, Z. 2011. Selection of façade’s alternatives of commercial and public buildings based on multiple criteria, International Journal of Strategic Property Management 15(2): 189-203. http://dx.doi.org/10.3846/1648715X.2011.586532

Schumpeter, J. A. 1934. The theory of economic development. Harvard University Press. 255 p.

Sjöholm, F. 1997. Technology gap, competition and spillovers from direct foreign investment: evidence from establishment data. EIJS, The European Institute of Japanese Studies, Strockholm, Sweden.

Smith, K. 2000. Innovation as a systemic phenomenon: rethinking the role of policy, Enterprise and Innovation Management Studies 1(1): 73-102. http://dx.doi.org/10.1080/146324400363536

Srinivas, S.; Sutz, J. 2005. Economic development and innovation: problem-solving in scarcity conditions, in DRUID Tenth Anniversary Summer Conference on Dynamics of Industry and Innovations, Networks and Systems, 2005, Copenhagen, Denmark.

Sutz, J. 2012. Measuring innovation in developing countries: some suggestions to achieve more accurate and useful indicators, International Journal of Technological Learning, Innovation and Development 5: 40-57.

UNESCO 1968. Provisional guide to the collection of science statistics. Paris: UNESCO. 
UNESCO 1978. Recommendation concerning the international standardization of statistics on science and technology. Paris: UNESCO.

UNESCO 1980. Manual for statistics on scientific and technological activities. Paris: UNESCO.

Weinthal, E.; Loung, P. J. 2006.Combating the resource curse: an alternative solution to managing mineral wealth, Perspective on Politics 4(1): 35-53. http://dx.doi.org/10.1017/S1537592706060051

Wu, J.; Zhou, Z.; Liang, L. 2010. Measuring the performance of Chinese regional innovation systems with two-stage DEA-based model, International Journal of Sustainable Society 2(1): 85-99. http://dx.doi.org/10.1504/IJSSOC.2010.030564

Zabala-Iturriagagoitia, J. M. 2008. Benchmaking regional innovation systems: the relevance of efficiency to their performance: PhD Dissertation. Universidad Politecnicade Valencia.

Zabala-Iturriagagoitiaa, J. M.; Voigta, P.; Gutiérrez-Graciaa, A.; Jiménez-Sáeza, F. 2007. Regional innovation systems: how to assess performance, Regional Studies 41(5): 661-672. http://dx.doi.org/10.1080/00343400601120270

Zadeh, L. A. 1965. Fuzzy sets, Information and Control 8(3): 338-353. http://dx.doi.org/10.1016/S0019-9958(65)90241-X

\section{APPENDIX A}

Innovation performance dimensions of Iran's provinces (sorted by catch-up index 2004-2007)

\begin{tabular}{cccccc}
\hline $\begin{array}{c}\text { Experimental } \\
\text { catch-up pattern } \\
-\begin{array}{c}\text { R\&D } \\
\text { - Second period }\end{array}\end{array}$ & $\begin{array}{c}\text { Catch-up } \\
\text { index } \\
\text { achievements } \\
\text { (2004-2007) }\end{array}$ & $\begin{array}{c}\text { Catch-up } \\
\text { index } \\
(2000-2003)\end{array}$ & Learning & Province \\
\hline & & 0.7608 & 0.7954 & -0.0346 & Kerman \\
\hline & & & & & \\
\hline
\end{tabular}


Continued Appendix A

\begin{tabular}{|c|c|c|c|c|c|}
\hline $\begin{array}{c}\text { Experimental } \\
\text { catch-up pattern } \\
--- \text { First period } \\
\text { Second period }\end{array}$ & $\begin{array}{c}\mathrm{R} \& \mathrm{D} \\
\text { achievements }\end{array}$ & $\begin{array}{l}\text { Catch-up } \\
\text { index } \\
(2004-2007)\end{array}$ & $\begin{array}{c}\text { Catch-up } \\
\text { index } \\
(2000-2003)\end{array}$ & Learning & Province \\
\hline & 89.49 & 0.5982 & 0.4604 & 0.1378 & Isfahan \\
\hline & 35.25 & 0.5624 & 0.3538 & 0.2086 & Zanjan \\
\hline & 0.71 & 0.5449 & 0.7354 & -0.1905 & Hormozgan \\
\hline & 0.78 & 0.5405 & 0.7417 & -0.2012 & Golestan \\
\hline & 99.91 & 0.4983 & 0.5274 & -0.0291 & Markazi \\
\hline & 28.13 & 0.4708 & 0.4278 & 0.0430 & Fars \\
\hline & 7.25 & 0.4602 & 0.4749 & -0.0147 & Khuzestan \\
\hline & 27.84 & 0.4593 & 0.4332 & 0.0261 & West-Azerbaijan \\
\hline & 149.3 & 0.4551 & 0.5366 & -0.0815 & East-Azerbaijan \\
\hline
\end{tabular}


S. Ghazinoory, et al. Measuring innovation performance of developing regions ...

Continued Appendix A

\begin{tabular}{|c|c|c|c|c|c|}
\hline $\begin{array}{c}\text { Experimental } \\
\text { catch-up pattern } \\
---- \text { First period } \\
\text { Second period }\end{array}$ & $\begin{array}{c}\text { R\&D } \\
\text { achievements }\end{array}$ & $\begin{array}{c}\text { Catch-up } \\
\text { index } \\
(2004-2007)\end{array}$ & $\begin{array}{c}\text { Catch-up } \\
\text { index } \\
(2000-2003)\end{array}$ & Learning & Province \\
\hline
\end{tabular}

\begin{tabular}{llllll}
\hline & 42.86 & 0.4424 & 0.4265 & 0.0159 & \\
& & & & \\
& & &
\end{tabular}

$8.16 \quad 0.4309 \quad 0.6108 \quad 0.1801 \quad \begin{gathered}\text { Chaharmahal- } \\ \text { Bakhtiari }\end{gathered}$

\begin{tabular}{llllll}
\hline & 19.81 & 0.4095 & 0.4882 & -0.0787 & Lorestan \\
\hline
\end{tabular}

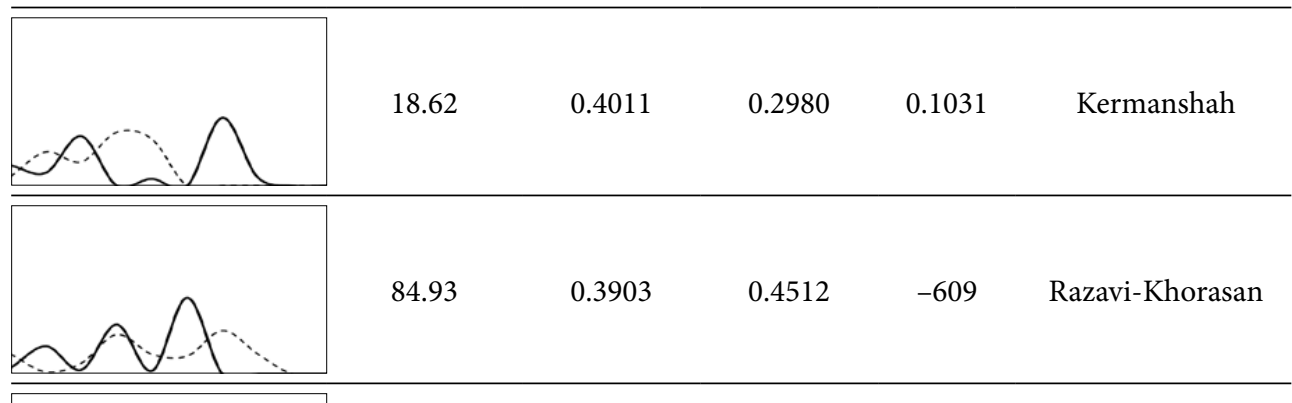

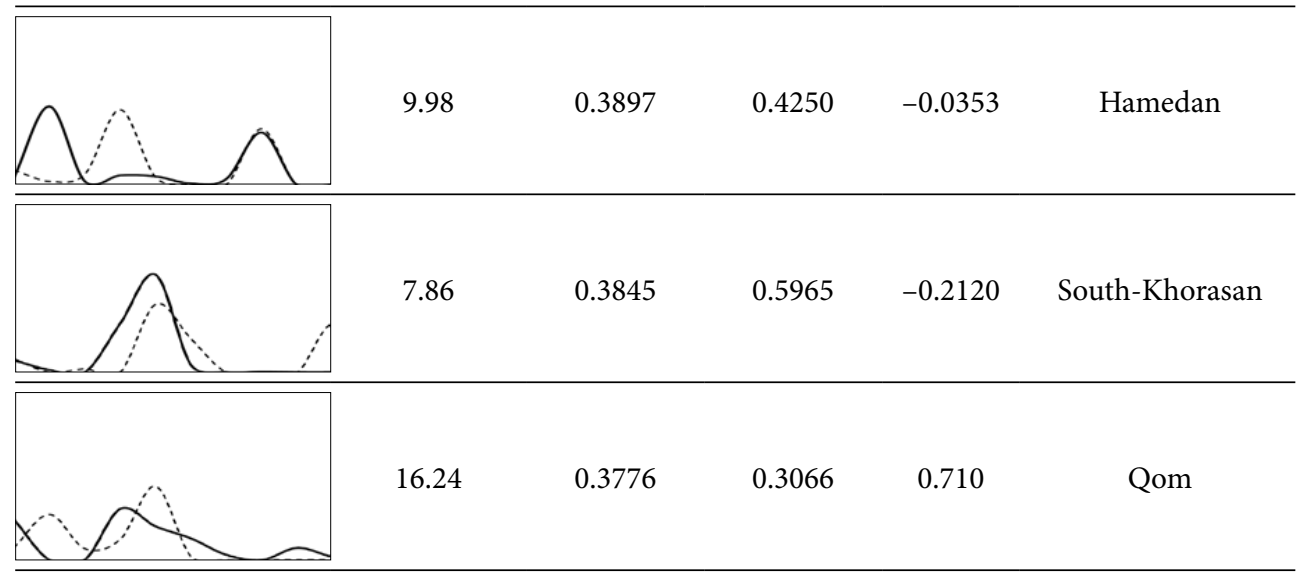


End of Appendix A

\begin{tabular}{|c|c|c|c|c|c|}
\hline $\begin{array}{c}\text { Experimental } \\
\text { catch-up pattern } \\
--- \text { First period } \\
\text { Second period }\end{array}$ & $\begin{array}{c}\text { R\&D } \\
\text { achievements }\end{array}$ & $\begin{array}{c}\text { Catch-up } \\
\text { index } \\
(2004-2007)\end{array}$ & $\begin{array}{l}\text { Catch-up } \\
\text { index } \\
(2000-2003)\end{array}$ & Learning & Province \\
\hline
\end{tabular}

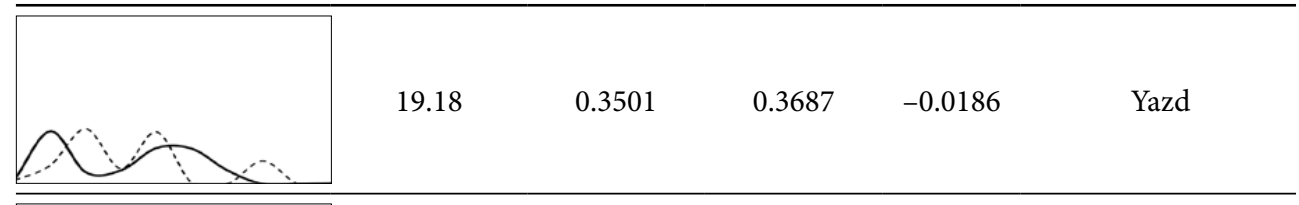

\begin{tabular}{ccccccc}
\hline & 1.58 & 0.3372 & 0.4574 & -0.1202 & $\begin{array}{c}\text { Kohgilouye-Boir- } \\
\text { Ahmad }\end{array}$ \\
\hline
\end{tabular}

\begin{tabular}{|c|c|c|c|c|c|}
\hline & 44.49 & 0.3270 & 0.3432 & -0.0162 & Guilan \\
\hline
\end{tabular}

ר

\begin{tabular}{llllll} 
& & & & & \\
& 11.09 & 0.3017 & 0.5362 & -0.2345 & North-Khorasan \\
\hdashline & $\ddots$ & & & \\
\hline
\end{tabular}

\begin{tabular}{|c|c|c|c|c|c|}
\hline & 215.35 & 0.2946 & 0.3371 & -0.0425 & Semnan \\
\hline & 72.47 & 0.2874 & 0.4985 & -0.2111 & Ardabil \\
\hline & 30.55 & 0.2484 & 0.4260 & -0.1776 & Kurdistan \\
\hline
\end{tabular}




\section{APPENDIX B}

\section{Innovation performance measure of Iran's provinces}

\begin{tabular}{|c|c|c|c|c|c|}
\hline & \multirow[b]{2}{*}{ Province } & \multicolumn{4}{|c|}{ Membership score in sets } \\
\hline & & $\begin{array}{l}\text { Learning } \\
\text { (L) }\end{array}$ & $\begin{array}{l}\text { Catching-up } \\
\text { (C) }\end{array}$ & $\begin{array}{l}\text { Research- } \\
\text { developing } \\
\text { (RD) }\end{array}$ & $\begin{array}{l}\text { Innovative } \\
\text { (I) }\end{array}$ \\
\hline $\begin{array}{l}\text { Innovative regions } \\
\mu_{x}(I) \geq 0.95\end{array}$ & Tehran & 0.96 & 0.95 & 0.57 & 0.95 \\
\hline \multirow{4}{*}{$\begin{array}{l}\text { Somewhat } \\
\text { innovative } \\
\text { regions } \\
0.50<\mu_{x}(\mathrm{I})<0.95\end{array}$} & Isfahan & 0.89 & 0.95 & 0.83 & 0.89 \\
\hline & Zanjan & 0.96 & 0.87 & 0.19 & 0.87 \\
\hline & Mazandaran & 0.82 & 0.99 & 0.3 & 0.82 \\
\hline & Boushehr & 0.65 & 1 & 0.01 & 0.65 \\
\hline \multirow{16}{*}{$\begin{array}{l}\text { Somewhat } \\
\text { non-innovative } \\
\text { regions } \\
0.05<\mu_{x}(\mathrm{I})<0.50\end{array}$} & Fars & 0.66 & 0.39 & 0.1 & 0.39 \\
\hline & Guilan & 0.38 & 0.07 & 0.37 & 0.37 \\
\hline & Khuzestan & 0.39 & 0.36 & 0.01 & 0.36 \\
\hline & West-Azerbaijan & 0.6 & 0.35 & 0.1 & 0.35 \\
\hline & Ghazvin & 0.56 & 0.3 & 0.33 & 0.33 \\
\hline & Markazi & 0.29 & 0.49 & 0.88 & 0.29 \\
\hline & Kerman & 0.26 & 1 & 0.03 & 0.26 \\
\hline & Semnan & 0.22 & 0.04 & 1 & 0.22 \\
\hline & Kermanshah & 0.82 & 0.18 & 0.04 & 0.18 \\
\hline & Hamedan & 0.26 & 0.16 & 0.02 & 0.16 \\
\hline & Razavi-Khorasan & 0.14 & 0.16 & 0.8 & 0.14 \\
\hline & Qom & 0.74 & 0.14 & 0.03 & 0.14 \\
\hline & Yazd & 0.36 & 0.1 & 0.04 & 0.1 \\
\hline & Lorestan & 0.09 & 0.2 & 0.05 & 0.09 \\
\hline & East-Azerbaijan & 0.08 & 0.34 & 0.98 & 0.08 \\
\hline & Sistan - Baluchistan & 0.31 & 0.07 & 0.01 & 0.07 \\
\hline \multirow{8}{*}{$\begin{array}{l}\text { Non-innovative } \\
\text { regions } \\
\mu_{x}(\mathrm{I}) \leq 0.05\end{array}$} & Kohgilouye-Boir-Ahmad & 0.03 & 0.08 & 0.01 & 0.03 \\
\hline & Hormozgan & 0 & 0.79 & 0.01 & 0 \\
\hline & Golestan & 0 & 0.77 & 0.25 & 0 \\
\hline & Chaharmahal-Bakhtiari & 0 & 0.26 & 0.02 & 0 \\
\hline & South-Khorasan & 0 & 0.15 & 0.01 & 0 \\
\hline & Ardabil & 0 & 0.04 & 0.71 & 0 \\
\hline & North-Khorasan & 0 & 0.05 & 0.02 & 0 \\
\hline & Kurdistan & 0 & 0.02 & 0.13 & 0 \\
\hline
\end{tabular}


Sepehr GHAZINOORY is an Associate Professor at the Department of Information Technology Management, Tarbiat Modares University, Tehran, Iran. He received his BSc, MSc and PhD in Industrial Engineering from Iran University of Science and Technology (IUST). He has authored numerous books and articles about national innovation system of Iran, cleaner production, strategic planning and management of technology in Persian and English. He was also a Consultant to the Iran Presidential Technology Co-operation Office (TCO) for four years and Senior Consultant in formulating the Iran Nanotechnology National Initiative.

Parisa RIAHI has a PhD in Science and Technology Policymaking of Tarbiat Modares University, Tehran, Iran. She has authored some research papers on innovation systems, innovation policy and technology parks and co-authored a book on innovation systems in Persian. Her research is focused on different types of regional innovation system in Iran.

Adel AZAR is a Professor in the Department of Information Technology Management, Tarbiat Modares University, Tehran, Iran. He received his BSc, MSc and $\mathrm{PhD}$ in industrial management University of Tehran (UT). His research focus is on Quantitative management theory-new approach (fuzzy logic and neural network), Planning and optimal resource allocation, Performance evaluation and Decision making-MADM approach. He has authored 10 books in Persian and more than 60 research papers in Persian and English.

Tahereh MIREMADI is an Assistant Professor in Iranian Research Organization for Science and Technology. Her research focus is on Policy making and Political economy of technology development in Iran and has published several papers in English and Persian. 